\title{
Cash-based Responses in Emergencies: A Reply to Harvey
}

\section{Ugo Gentilini}

I think that Paul's and my views are convergent on the need to be context-specific and base transfer selection on appropriate analysis. A good starting point. However, there are some compelling issues on which our views diverge.

First, I am not convinced by a line of argument that implicitly makes food aid inappropriate because it is the dominant or default in humanitarian emergencies: in many such emergencies, food is the most appropriate response, be that by default or otherwise. If we exclude the unique post-Tsunami experience, the evidence base for cash in emergencies is somehow sparse and shows mixed results. Then the implication that cash is necessarily more appropriate in most emergencies is highly questionable. As Paul recognises, 'markets in developing countries are often weak and poorly integrated, and may be particularly constrained or disrupted in conflicts and during natural disasters'. So what is the basis to the claim that 'cash-based programming will continue to grow, probably at the expense of in-kind mechanisms in some contexts'? Put differently, where is the evidence that food transfers were so widely inappropriate that cash should be an alternative to (meaning a substitute for) food? Even if I am not representing the World Food Programme's (WFP) view in this note, I am personally glad that Paul often refers to Sharma (2006), given that this WFP-supported study is the most rigorous evaluation available of any cash transfer initiative. However, Paul gives a distorted picture when he uses it to support the evidence on cash-for-nutrition ('a switch from food to cash benefits was not likely to affect consumption significantly'): would anybody expect significant changes in consumption patterns in just 3 months?

\section{Reference}

Savage, K. and Umar E. (2006) Independent Evaluation of Oxfam GB Malawi's Cash Transfer Programme,
Second, I would not define cash as 'threatening' because it gives control to people. If it is argued that food could be re-sold by people and the proceeds used for any purpose (although less efficiently), then any form of aid would eventually be more or less threatening. Giving people control is not just a matter of money. And even in that case, cash provides choice but also transfers risk (of supply failures) directly to people. In emergency contexts, such risk is high. Contingency plans are supposed to insure against that risk, but there are cases where cash-based contingencies were neither effective for people nor efficient for NGOs (e.g. Zambia 2005/6). Arguably, more attention should be given to foodbased contingency plans.

Third, statements such as 'the reluctance to consider cash is also related to the underlying attitudes and assumptions that humanitarian aid practitioners have towards the people that they are trying to help' are unacceptable. To me, 'inappropriate attitudes' derive from assuming knowledge of what is best for people without consulting them and without undertaking proper assessments. For example, the evaluation of an Oxfam cash transfer scheme in Malawi reported that '.. despite the fact that the communities stated a preference for food aid, Oxfam felt that [cash] was an appropriate instrument to use and decided to go ahead with the project' (Savage and Umar 2006: 15). If food aid had been provided, as requested by people, it would have protected against the subsequent price shocks that largely wiped out people's purchasing power. This is even more striking if we consider that this pilot was designed without having undertaken an ex ante market assessment. Therefore, 'inappropriate attitudes' relate to the way assistance is provided, and not to what is provided.

Humanitarian Policy Group, London: Overseas

Development Institute 